\title{
Determination of solute transport parameters for remediation of hydrocarbons from ground water in Antarctica
}

\author{
Meenakshi Arora $^{1}$, Ian Snape ${ }^{2}$, Geoff W. Stevens ${ }^{1}$ \\ ${ }^{1}$ Melbourne School of Engineering University of Melbourne, Victoria 3010, Australia \\ ${ }^{2}$ Human Impacts Research Group, Australia Antarctic Division, Channel Highway, Kingston, \\ Tasmania, 7050, Australia
}

\begin{abstract}
There are many contaminated sites in Antarctica as a result of accidents or poor waste management. A significant proportion of the pollution is from oil and its derivatives and heavy metals. Although it's a common perception that hydrocarbon spills in frozen grounds are immobile, fuel components have been shown to be highly mobile in soils and sediments with low organic contents specifically during the summer snow melting season. The low temperature and low nutrient soils in cold regions make the natural attenuation rates much slower as compared to temperate climates. Therefore, more active remediation options are often sought for such sensitive areas. Permeable reactive barriers (PRB) are one such option. They are an in situ passive treatment technology that removes dissolved contaminants from polluted water through subsurface emplacement of reactive materials and are widely applied. But to install a successful $\mathrm{PRB}$ in cold regions, it is important to understand the flow path and solute transport mechanism in frozen including axial dispersion and the reaction of solute.

This paper will discuss about the modeling tool to determine the contaminant transport behavior with minimal amount of data requirements, as acquiring significant amount of field data in such environments is practically not often possible. This study also investigates the impact of temperature and axial flow on the sorption column performance to adsorb hydrocarbons by studying breakthrough point and breakthrough curve at various flow rates and development of a model to predict the solute transport parameters. Toluene has been used as a representative soluble aromatic hydrocarbon in this study. Inverse modeling has been utilized using the computer program CXTFIT to determine the variable parameters, axial dispersion coefficient and porosity. A set of partial differential equations was solved to describe the solute flow through, with appropriate initial and boundary conditions in order to develop a model to predict the future $\mathrm{PRB}$ and its performance in the field.
\end{abstract}

Keywords: Permeable reactive barrier, Solute transport, Modeling, Hydrocarbons, Porosity 


\section{Introduction}

Permeable reactive barriers (PRB) are considered the most practicable approach to clean up the oil spill sites in cold regions due to its minimal impact on the environment and minimal power requirements \& attention needed (Snape et al, 2001). But finding suitable materials for the cold region PRB is the key to its successful implementation in such remote areas. Various studies have shown that granular activated carbon (GAC) can successfully remove hydrocarbons from water (Valderrama et al, 2008, Chatzopoulos and Varma, 1995, Hindarso et al, 2001, Arora et al, 2010). Although batch equilibrium and kinetic studies are excellent means to describe the ion exchange characteristics of GAC, understanding the contaminant transport characteristics of flow through a porous medium is imperative to the design of a PRB. While the understanding of exchange processes gained from batch tests is theoretically sufficient to describe and predict exchange performance, in practice this understanding is not directly applicable to dynamic systems of flow through porous media. Column testing is generally considered to be a more realistic simulation of field conditions and facilitate the generation of realistic PRB design parameters and allow the development of a model to predict the performance of PRB (USEPA, 1998). Furthermore, parameters characterizing an adsorbent determined from batch tests can differ significantly compared to those measured from column techniques (Plassard et al., 2000; Inglezakis and Grigoropoulou, 2003). As column tests are more costly, time consuming and difficult to perform than batch test methods, and processes affecting the behavior of solutes flowing through a column are complicated and not as well understood as for batch conditions, the theoretical understanding and modeling of solute transport is less well developed than for batch systems (Helfferich, 1962).

Therefore, it's important to understand the solute transport mechanism in GAC fixed beds and to develop a model describing solute transport in real situations to facilitate the GAC PRB design and implementation in cold regions. This study investigates the impact of temperature and axial flow on the GAC column performance to adsorb hydrocarbons by studying breakthrough point and breakthrough curve at various flow rates and development of a model to predict the solute transport parameters. Toluene has been used as a representative soluble aromatic hydrocarbon in this study.

\section{Materials and methods}

The granular activated carbon (GAC), produced from coconut husk was obtained from Pica Activated Carbon P/L. The adsorptive properties of GAC are due to high surface area due to its micro porous structure (Yang, 2003; Yue and Econome, 2005). High Performance Liquid Chromatography (HPLC) was used to determine the concentrations of toluene in solution before and after the adsorption equilibrium was reached. The analysis was performed as explained by Arora et al, 2010.

\section{Axial dispersion tests}

Axial dispersion of fluid in the GAC column was studied by spiking the de-ionized water with nitrate and adjusting the $\mathrm{pH}$ to 11.5 by addition of $\mathrm{NaOH}$, as GAC becomes inert to nitrate at $\mathrm{pH}$ above 11.0 (Hager and Fredrick, 1981). The column was saturated with $50 \mathrm{mg} / 1$ nitrate solution and then feed solution was replaced by de-ionized water at time zero. The effluent samples were collected every two minutes and analyzed for nitrate concentration until all the nitrate solution was ejected. CXTFIT, a code developed by the U.S. Agriculture Department for estimating the solute transport parameters using a nonlinear leastsquares parameter optimization method was used to solve the inverse axial-dispersion problem and quantify the axial dispersion coefficient $\left(D_{1}\right)$ at various flow rates (Toride et al, 1999).

\section{Toluene Column tests}

Fixed bed column experiments for toluene sorption were conducted using a vertical glass column of 120 $\mathrm{mm}$ height and $35 \mathrm{~mm}$ internal diameter. Packed GAC had a porosity of 0.39 and bulk density $0.285 \mathrm{~g} / \mathrm{cm}^{3}$. The $1.0 \mathrm{mmol} / 1$ toluene solution was introduced in the column in up flow direction at flow rates between 13.63 to 27.27 pore volume per hour $(\mathrm{PV} / \mathrm{h})$ equivalent to superficial feed velocities between 0.0173 to $0.0347 \mathrm{~cm} / \mathrm{s}$. The water samples were collected at column exit $(120 \mathrm{~mm})$ at appropriate intervals and analyzed for toluene concentration. The tests were carried out in duplicate at $20^{\circ}$ and $4^{0} \mathrm{C}$.

\section{Determination of Axial dispersion coefficient $D_{1}$}

Assuming that solute transport is occurring in saturated, homogeneous, isotropic porous media under steady-state uniform flow and that Darcy's law applies, the advection-dispersion equation (ADE) for the 
Arora et al., Determination of solute transport parameters for remediation of hydrocarbons...

transport of a non-reactive solute in the axial (x-axis) direction can be expressed as: (Freeze and Cherry,1979 and Bear 1988)

$\frac{\partial C}{\partial t}=D_{l} \frac{\partial^{2} C}{\partial x^{2}}-\bar{v} \frac{\partial C}{\partial x}$

where $\mathrm{C}$ is the toluene concentration in bulk solution, $\mathrm{D}_{1}$ is the axial dispersion coefficient, $x$ is the distance taken along the flow line, $\bar{v}$ is the average pore velocity. $\mathrm{D}_{1}$ is a macroscopic parameter describing a number of micro scale dispersion and diffusion processes.

Inverse modeling was utilized using the computer program CXTFIT to determine the variable parameters $\left(D_{1}\right.$ and $n$ ), where ' $n$ ' is the porosity, by fitting a solution to the Eqn 1 from axial dispersion tests (Freeze and Cherry, 1979):

$\frac{C}{C_{0}}=\frac{1}{2}\left[\operatorname{erfc}\left(\frac{x-\bar{v} t}{2 \sqrt{D_{l} t}}\right)+\exp \left(\frac{\bar{v} x}{D_{l}}\right) \operatorname{erfc}\left(\frac{x+\bar{v} t}{2 \sqrt{D_{l} t}}\right)\right]$

\section{Reactive transport in the Column}

The loss or gain of solute within an elemental volume of porous media can occur from chemical reactions that take place within the pore water or because of transfer of solute to or from the solid phase (Freeze and Cherry, 1979). The loss of solute from solution due to adsorption can be described by including an additional term in Eqn 1 to describe the effect of the rate of change in solute concentration in the solid phase. Equation 1 then becomes the advection-dispersion-reaction solute transport equation (ADRE), which is:

$$
\frac{\partial C}{\partial t}=D_{l} \frac{\partial^{2} C}{\partial x^{2}}-\bar{v} \frac{\partial C}{\partial x}-\frac{\rho_{b}}{n} \frac{\partial q}{\partial t}
$$

The term $\frac{\rho_{b}}{n} \frac{\partial q}{\partial t}$ is the rate of change in solution concentration due to sorption processes, where $\rho_{b}$ is the bulk density of the GAC column and q is the toluene concentration on GAC.

In this study, three approaches (models) were utilized to determine ' $q$ ' values:

i) Under equilibrium conditions, where the sorption occurs instantaneously and local equilibrium between the liquid and solid phase solute is maintained, and the spread of the breakthrough curve is governed by axial dispersion only. The local equilibrium can be described by a linear relationship between solute concentrations in solid and aqueous phases as:

$q=K_{d} C$

where $K_{d}$ is a constant and commonly known as the distribution coefficient. The assumption of linear sorption has major drawbacks as there is no limit on solute solid concentration, which is clearly not the case in real sorption systems, and the relationship between fluid and solid solute concentrations is rarely found to be linear (Fetter, 1993).

ii) A more realistic approach is to describe the relationship between fluid and solid phase solute concentrations by the Langmuir or Freundlich sorption isotherm. The Langmuir isotherm equation relates the solute concentrations in solid and aqueous phases as:

$$
q=\frac{K_{l} M C_{e}}{1+K_{l} C_{e}}
$$

Where $K_{l}$ and $M$ are Langmuir constants and $C_{e}$ is the equilibrium toluene concentration in solution and have been determined for toluene sorption on GAC (Arora et al, 2010).

iii) For non-equilibrium sorption, mass transfer processes govern the rate of exchange, which is proportional to the distance the system is from the equilibrium. For particle diffusion, it is the difference between the average solute concentration within the zeolite and the solute concentration at the particle surface (Helfferich, 1962). A linear driving force (LDF) relation is commonly used to approximate the particle diffusion controlled rate of mass transfer from the liquid to solid phase as (Helfferich, 1962; Semmens et al, 1978; Worch, 2003): 
Arora et al., Determination of solute transport parameters for remediation of hydrocarbons...

$$
\frac{\partial q}{\partial t}=\frac{60 D_{p}}{4 d_{p}^{2}}\left(q_{e}-\hat{q}\right)
$$

where $q_{e}$ is zeolite loading at the particle surface that is in equilibrium with the solution, $\hat{q}$ is the average solid concentration, $D_{p}$ is particle diffusion coefficient and $d_{p}$ is the mean particle diameter. The term $\frac{60 D_{p}}{4 d_{p}{ }^{2}}$ is analogous to a mass transfer coefficient, $N_{p}$.

Mathematica, a general purpose mathematical program (Wolfram, 1996) was used to solve the set of partial differential equations 3, 4, 5 and 6 to describe the solute flow through a GAC column, with appropriate initial and boundary conditions in order to develop a model to describe laboratory scale column tests, and provide a basis for the future development of a model to predict the performance of a GAC PRB.

\section{Results}

\section{Axial Dispersion Coefficient}

Axial dispersion coefficients $\left(\mathrm{D}_{1}\right)$ and porosity $(\mathrm{n})$ at various flow rates were determined at $20^{\circ}$ and $4^{0} \mathrm{C}$ by solving Eqn. 2 using a computer program, CXTFIT. The data generated by CXTFIT showed an excellent fit to the experimental $\left(\mathrm{R}^{2}=0.993\right.$ to 0.998$)$ data (Fig. 1). The axial dispersion coefficient increased with increase in flow rate and varied from $0.812 \times 10^{-6}$ to $4.88 \times 10^{-6} \mathrm{~m}^{2} / \mathrm{s}$ at various flow rates and temperatures (Table 1). Table 1 also shows that column Peclet numbers were moderately high (up to 68) at $4^{0} \mathrm{C}$ and increased with the flow rate, indicating that advective solute transport is the significant transport mechanism at $4^{0} \mathrm{C}$ with a greater impact of axial dispersion at $20^{\circ} \mathrm{C}$ (Peclet no 29-31). Also, the advective solute transport becomes increasingly dominant at higher flow rates. The column Peclet number represents the relative effect of advective solute transport compared to dispersive transport, and is given by:

$P_{e}=\frac{\bar{v} L}{D_{l}}$

Table 1: Axial dispersion test parameters for toluene sorption on GAC at 20 and $4^{0} \mathrm{C}$.

\begin{tabular}{|l|l|l|l|l|l|l|}
\hline \multirow{2}{*}{$\begin{array}{l}\text { Temperature } \\
(\mathbf{(} \mathbf{C})\end{array}$} & Flow rate & $\begin{array}{l}\text { Pore velocity } \\
(\mathbf{m} / \mathbf{h})\end{array}$ & $\mathbf{D}_{\mathbf{l}}\left(\mathbf{m}^{\mathbf{2}} / \mathbf{s}\right)$ & $\mathbf{R}_{\mathbf{e}}$ & $\mathbf{P}_{\mathbf{e}}$ \\
\cline { 2 - 8 } & $\mathbf{P V} / \mathbf{h}$ & $\mathbf{l} / \mathbf{h}$ & & & \\
\hline \multirow{4}{*}{40} & 3.95 & 0.18 & 0.49536 & $3.428 \mathrm{E}-06$ & 0.1277 & 29.30126 \\
\cline { 2 - 7 } & 6.59 & 0.3 & 0.798 & $4.025 \mathrm{E}-06$ & 0.205718 & 30.31469 \\
\cline { 2 - 7 } & 9.23 & 0.42 & 1.104 & $4.880 \mathrm{E}-06$ & 0.284602 & 30.67715 \\
\hline \multirow{4}{*}{4} & 3.95 & 0.18 & 0.48528 & $8.122 \mathrm{E}-07$ & 0.058464 & 64.00167 \\
\cline { 2 - 7 } & 6.59 & 0.3 & 0.7878 & $1.506 \mathrm{E}-06$ & 0.094909 & 65.70773 \\
\cline { 2 - 7 } & 9.23 & 0.42 & 1.0686 & $1.878 \mathrm{E}-06$ & 0.128738 & 67.81806 \\
\hline
\end{tabular}

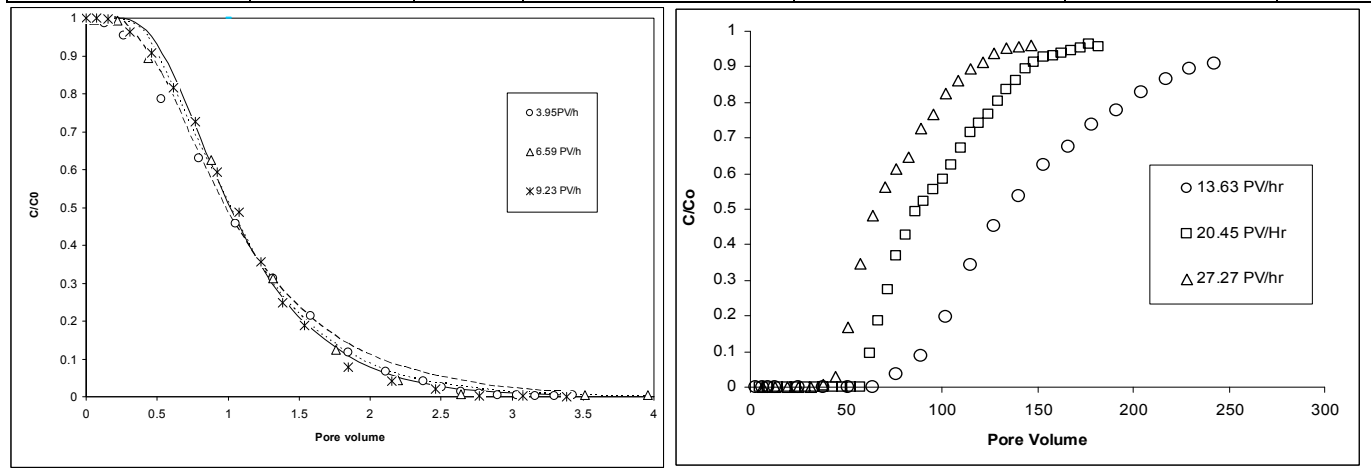

Fig. 1: The effect of flow rate on axial dispersion in packed column at $20^{\circ} \mathrm{C}$. The lines represent the CXTFIT model fit.
Fig. 2: Toluene breakthrough curves of GAC columns at $20^{\circ} \mathrm{C}$. Initial toluene concentration $=1 \mathrm{mmol} / 1$. 
At high Peclet numbers $\left(P_{e} \geq 50\right)$ advection dominates the solute transport process; while at low Peclet numbers $\left(P_{e} \leq 1\right)$ dispersion/diffusion dominates (Shackelford, 1994).

In order to model the flow through porous media, $D_{1}$ must be known for each given flow regime. For a set of known media characteristics (particle size) and a set of operating conditions (temperature and solution characteristics), it is convenient to relate axial dispersion to some measure of velocity - which can easily be measured or calculated. In this case, axial dispersion can be related to the Reynolds number (Re), which can easily be calculated from the flow velocity for a specific system of known temperature, solution viscosity and density, and particle size. The Reynolds number is a dimensionless parameter that expresses the ratio of inertial to viscous forces during flow; and is used to distinguish between laminar flow, when Darcy's law applies, and turbulent flow regimes (Freeze and Cherry, 1979). The Reynolds number for flow in porous media is:

$R_{e}=\frac{\rho v d}{\mu}$

where $\rho$ and $\mu$ are water density and viscosity, and $d$ is mean particle diameter.

\section{Breakthrough Curves}

Breakthrough curves at various flow rates at a temperature of $20^{\circ} \mathrm{C}$ are presented in fig. 2. Table 2 shows that the time to breakthrough (at $\mathrm{C} / \mathrm{C}_{0}=0.1$ ) and the corresponding fixed bed operating capacity $\left(\right.$ at $\mathrm{C} / \mathrm{C}_{0}=$ 0.99 ) decreases with increasing flow rate. The fixed bed saturation capacities are approximately $30-60 \%$ lower that the capacity expected from equilibrium studies depending upon the feed flow rates. A steeper and faster breakthrough curve was observed at low temperature for similar flow conditions and feed concentrations.

Table 2: Fixed -bed breakthrough points and capacities. Breakthrough is taken when $\mathrm{C} / \mathrm{C}_{0}=0.1$ and saturation at $\mathrm{C} / \mathrm{C}_{0}=0.99$. Batch estimated maximum capacities are $2.354 \mathrm{mmol} /$ and $1.778 \mathrm{mmol} / \mathrm{g}$ at $20^{\circ} \mathrm{C}$ and $4^{0} \mathrm{C}$ respectively (Arora et al, 2010).

\begin{tabular}{|l|l|l|l|l|l|}
\hline $\begin{array}{l}\text { Feed } \\
\text { Temp. } \\
\left({ }^{\mathbf{0}} \mathbf{C}\right)\end{array}$ & $\begin{array}{l}\text { Feed Flow } \\
\text { rate (PV/h) }\end{array}$ & $\begin{array}{l}\text { Breakthrough } \\
\text { point (PV) }\end{array}$ & $\begin{array}{l}\text { Saturation } \\
\text { point (PV) }\end{array}$ & $\begin{array}{l}\text { Breakthrough } \\
\text { capacity (mmol/l) }\end{array}$ & $\begin{array}{l}\text { Saturation } \\
\text { capacity } \\
\text { (mmol/l) }\end{array}$ \\
\hline \multirow{5}{*}{20} & 13.63 & 95.41 & 336 & 0.889 & 1.461 \\
\cline { 2 - 6 } & 20.45 & 63.6 & 227.16 & 0.586 & 0.967 \\
\cline { 2 - 6 } & 27.27 & 49 & 168 & 0.453 & 0.720 \\
\hline \multirow{5}{*}{4} & 13.63 & 68 & 177 & 0.727 & 1.073 \\
\cline { 2 - 6 } & 20.45 & 45 & 140 & 0.476 & 0.707 \\
\cline { 2 - 6 } & 27.27 & 36 & 104 & 0.372 & 0.524 \\
\hline
\end{tabular}

One dimensional sorption equilibrium modeling was performed using distribution coefficient, $\mathrm{K}_{\mathrm{d}}$ values and batch-estimated Langmuir constants $\left(\mathrm{K}_{1}\right.$ and $\left.\mathrm{M}\right)$ as determined by Arora et al 2010. Solute transport modeling under non-equilibrium conditions was also performed using Langmuir constants from batch tests and the mass transfer coefficient based on the particle diffusion coefficient estimated from kinetics data (Arora et, 2010). The results show that the linear sorption equilibrium equation (Eq 3 and 4) using the distribution coefficient, $K_{d}$ fails to predict the breakthrough point and curve shape. By using the Langmuir sorption equilibrium ADRE equation (Eq 3 and 5) and the Langmuir parameters $\mathrm{K}_{1}$ and $\mathrm{M}$, the model satisfactorily describes the experimental breakthrough point and curve shape (Fig 3) at both the temperatures. The non equilibrium mass transfer model (Eq. 3 and 6) using Langmuir parameters could not predict either the breakthrough point or the curve shape.

\section{Discussion}

For a given material and the solvent system, theoretically the equilibrium and exchange parameters determined from batch and fixed bed studies should be the same (Helfferich, 1962). However, the column capacities of GAC are approx. 30-60\% lower than the batch estimated values which are in line with the findings of other researchers (Ingelzakis et al, 2002, Abusafa and Yucel, 2002). The lower values of the 
Langmuir constant, $\mathrm{K}_{1}$ in fixed bed systems can be attributed to the differences in local equilibrium conditions that exist in each system. Also, the column-estimated values might be lower than the real saturation capacity because of the low concentration gradients, and possible continual slow diffusion into the particles after apparent fixed-bed saturation has been reached (Weber and Wang, 1987).

Additionally, the measured column capacity can be reduced due to the formation of hydraulic dead zones from channeling and preferential flow which physically limits the ability of solute to reach the sorption sites on a portion of sorbent particles (Hlavay et al, 1982). Flow conditions also influence the sorption characteristics (like capacities and particle diffusion coefficients) in columns (Inglezakis and Grogoropoulou, 2003, Lehmann et al, 2001). Also, Weber and Smith, 1987 found that in the initial stage of breakthrough using small columns, film diffusion is thought to dominate, irrespective of the mass transfer processes that occur later.
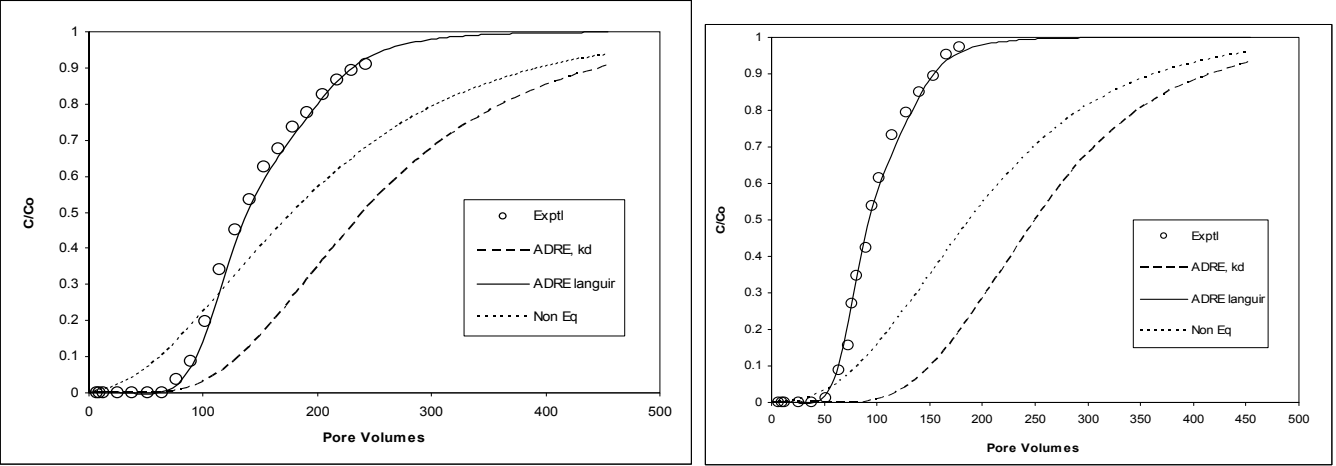

Fig. 3: The experimental data of fixed bed column tests and the breakthrough curves generated by various models at $20^{\circ} \mathrm{C}$ and $4^{0} \mathrm{C}$.

\section{PRB Design implications}

Though the laboratory studies reveal that GAC columns can successfully retain soluble hydrocarbons (toluene) and the one-dimensional Langmuir sorption equilibrium model can describe the column performance, there will a significant disparity in the hydro geological conditions in the lab scale columns and PRB in Antarctica/Arctic, where the flows will be highly dynamic and variable and may contain variable mix of contaminants. The freeze-thaw cycles may lead to particle sorting, ice lens formation and preferential flow channels resulting in increased axial dispersion and reduced capacity and life of the barrier. The PRB performance would also be affected as the particle size distribution of GAC changes due to material break up, loss of fines and particle sorting.

All these factors should be considered while designing a cold region PRB. The binary system used in this study is relatively simple as compared to the natural waters in contaminated sites like Main Power House at Casey, old Casey and Wilkes in Antarctica or other sites in Arctic with highly variable concentrations and flow rates and significant sea spray. Though the model should be able to predict the PRB performance in field conditions, further kinetic and fixed bed studies may be necessary to describe the solute transport in complex natural systems.

\section{Conclusions}

This study shows that low temperature detrimentally affects the sorption of toluene from water in fixed bed columns and therefore will have a significant influence on the design of a cold region PRB for hydrocarbon removal. Fixed bed breakthrough capacities and saturation capacities at $4^{0}$ are significantly lower than at $20^{\circ} \mathrm{C}$. The saturation capacity decreases with increased flow rates. Fixed-bed sorption parameters are significantly different from batch estimated values, with the capacity of GAC in fixed beds approx. 30-60\% of the capacity in batch system. An equilibrium sorption model for solute transport using Langmuir parameters estimated by batch tests can successfully describe the fixed bed performance in a binary system. However, further work on uptake of toluene on GAC in multi-component system may be necessary to describe the solute transport in complex natural systems. 
Arora et al., Determination of solute transport parameters for remediation of hydrocarbons...

\section{Acknowledgements}

This study was supported by the Particulate Fluids Processing Centre, a special Research Centre of Australian Research Council and Australian Antarctic Division.

\section{References}

- Abusafa, A. and Yucel, H. (2002). Removal of 137Cs from aqueous solutions using different cationic forms of a natural zeolite: clinoptilolite. Separation \& Purification Technology. 28, 103116

- Arora, M., Snape, I, Stevens, G.W., 2010. The effect of temperature on toluene sorption by granular activated carbon and its use in permeable reactive barrier in cold regions, Cold Regions Science and Technology, 66........

- Chatzopoulos, D. and Varma, A, 1995. Aqueous-phase adsorption and desorption of toluene in activated carbon fixed beds: experiments and model, Chemical Engineering Science, 50, 127-141.

- Fetter, C.W. (1993). Contaminant hydrogeology. Macmillan Publishing Company

- $\quad$ Freeze, R.A. and Cherry, J.A. (1979). Groundwater. Prentice-Hall

- Hager, D.G. and R.J. Fredrick. 1981. Water treatment for selective removal of nitrates. US Patent 4267057.

- Helfferich, F. (1962). Ion exchange. McGraw-Hill

- Hindarso,H, Ismadji, S., Wicaksana, F., Mudjijati and Indraswati, N., 2001. Adsorption of Benzene and Toluene from aqueous solution onto Granular Activated Carbon. Journal of Chemical and Engineering Data, 46,788-791.

- Hlavay, J., Vigh, G., Olaszi, V. and Inczedy, J. (1982). Investigations on natural Hungarian zeolite for ammonia removal. Water Research. 16, 417-420

- Inglezakis, V.J. and Grigoropoulou, H.P. (2003). Modeling of ion exchange of $\mathrm{Pb}^{2+}$ in fixed beds of clinoptilolite. Microporous and Mesoporous Materials. 61, 273-282

- Inglezakis, V.J., Loizidou, M.D. and Grigoropoulou, H.P. (2002). Equilibrium and kinetic ion exchange studies of $\mathrm{Pb}^{2+}, \mathrm{Cr}^{3+}, \mathrm{Fe}^{3+}$ and $\mathrm{Cu}^{2+}$ on natural clinoptilolite. Water Research. 36, 27842792

- Lehmann, M., Zouboulis, A.I. and Matis, K.A. (2001). Modelling the sorption of metals from aqueous solutions on goethite fixed-beds. Environmental Pollution. 113, 121-128

- Plassard, F., Winiarski, T. and Petit-Ramel, M. (2000). Retention and distribution of three heavy metals in a carbonated soil: comparison between batch and unsaturated column studies. Journal of Contaminant Hydrology. 42, 99-111

- Semmens, M.J., Booth, A.C. and Tauxe, G.W. (1978). Clinoptilolite column ammonia removal model. Journal of the Environmental Engineering Division, ASCE. April, 231-244

- Snape, I., Morris, C.E. and Cole, C.M. (2001a). The use of permeable reactive barriers to control contaminant dispersal during site remediation in Antarctica. Cold Regions Science and Technology. 32, 157-174.

- $\quad$ Toride, N., Leiji, F.J. and van Genuchten, M.T. (1999). The CXTFIT code for estimating transport parameters from laboratory or field tracer experiments. Version 2.1. U.S Salinity Laboratory, U.S Department of Agriculture. Research Report No. 137.

- USEPA, 1998. Permeable reactive barrier technologies for contaminant remediation. U.S. Environmental Protection Agency. 600R98125

- Valderrama, C., Gamisans, X., Heras, X., Farrán, A. and Cortina JL, 2008. Sorption kinetics of polycyclic aromatic hydrocarbons removal using granular activated carbon: intraparticle diffusion coefficients. Journal of Hazardous Materials, 15;157, 386-96.

- Weber, W.J.J. and Wang, C.K. (1987). A microscale system for estimation of model parameters for fixed-bed adsorbers. Environmental Science \& Technology. 21, 1096-1102

- Wolfram, S. (1996). The Mathematica book. $3^{\text {rd }}$ ed. Wolfram Media/Cambridge University Press

- Worch, E. (2003). Modelling the solute transport under nonequilibrium conditions on the basis of mass transfer equations. Journal of Contaminant Hydrology. 68, 97-120

- Yang, Ralph T., 2003. Adsorbents. Fundamentals and Applications. John Wiley \& Sons, Inc., Hoboken, New Jersey.

- Yue, Z., Economy, J., 2005. Nanoparticle and nanoporous carbon adsorbents for removal of trace organic contaminants from water. Journal of Nanoparticle Research 7, 477-487. 